OPEN ACCESS

Edited by:

Tao Xu,

Anhui Medical University, China

Reviewed by:

Guang-Bo Ge,

Shanghai University of Traditional Chinese Medicine, China

Lauren Gollahon,

Texas Tech University, United States

*Correspondence:

Zichao Chen

chenzichao11@126.com

Dongmei Q

qidm119@163.com

Zhen Zhang

zhangzhen19801981@126.com

Specialty section:

This article was submitted to

Ethnopharmacology,

a section of the journal

Frontiers in Pharmacology

Received: 05 July 2021 Accepted: 18 November 2021 Published: 03 December 2021

Citation:

Zhao W, Liu J, Li Y, Chen Z, Qi D and Zhang $Z$ (2021) Immune Effect of Active Components of Traditional Chinese Medicine on Triple-Negative

Breast Cancer.

Front. Pharmacol. 12:731741. doi: 10.3389/fphar.2021.731741

\section{Immune Effect of Active Components of Traditional Chinese Medicine on Triple-Negative Breast Cancer}

\author{
Wenjie Zhao ${ }^{1,2}$, Jinhua Liu ${ }^{1}$, Yaqun $\mathrm{Li}^{1}$, Zichao Chen ${ }^{1,3 *}$, Dongmei $Q i^{1,3 *}$ and Zhen Zhang ${ }^{1 *}$ \\ ${ }^{1}$ Innovation Research Institute of Traditional Chinese Medicine, Shandong University of Traditional Chinese Medicine, Jinan, \\ China, ${ }^{2}$ College of Chinese Medicine, Shandong University of Traditional Chinese Medicine, Jinan, China, ${ }^{3}$ Experimental Center, \\ Shandong University of Traditional Chinese Medicine, Jinan, China
}

Triple-negative breast cancers are heterogeneous, poorly prognostic, and metastatic malignancies that result in a high risk of death for patients. Targeted therapy for triplenegative breast cancer has been extremely challenging due to the lack of expression of estrogen receptor, progesterone receptor, and human epidermal growth factor receptor 2. Clinical treatment regimens for triple-negative breast cancer are often based on paclitaxel and platinum drugs, but drug resistance and side effects from the drugs frequently lead to treatment failure, thus requiring the development of new therapeutic platforms. In recent years, research on traditional Chinese medicine in modulating the immune function of the body has shown that it has the potential to be an effective treatment option against triplenegative breast cancer. Active components of herbal medicines such as alkaloids, flavonoids, polyphenols, saponins, and polysaccharides have been shown to inhibit cancer cell proliferation and metastasis by activating inflammatory immune responses and can modulate tumor-related signaling pathways to further inhibit the invasion of triplenegative breast cancer. This paper reviews the immunomodulatory mechanisms of different herbal active ingredients against triple-negative breast cancer and provides an outlook on the challenges and directions of development for the treatment of triplenegative breast cancer with herbal active ingredients.

Keywords: triple-negative breast cancer, traditional Chinese medicine, herbal remedies active ingredients, tumor immunity, anti-tumor

\section{INTRODUCTION}

Breast cancer is a serious threat to women's life and health safety, especially triple-negative breast cancer (TNBC). The main feature of the disease is the lack of expression of estrogen receptor, progesterone receptor, and human epidermal growth factor receptor 2 (HER2) (Pareja and Reis-Filho, 2018). Neither endocrine therapy nor conventional targeted therapy is the best treatment (Goto et al., 2018). Chemotherapy is still the mainstay of advanced TNBC with paclitaxel/anthracycline-containing agents as the chemotherapy of choice, and platinum-based agents in combination with paclitaxel as an effective alternative adjuvant chemotherapy option for patients with operable TNBC (Coates et al., 2015; Yu et al., 2020). But these drugs were not developed as precise treatments based on the genetic and hereditary characteristics of TNBC itself, although the above regimens have resulted in prolonged survival cycles, the toxic effects are heavy and still not tolerated by some patients (Goto et al., 2018). Without other effective approaches, it may mean a poor prognosis. There is an urgent need to find a new effective anti-TNBC drug with few side effects (Chu et al., 2003). 


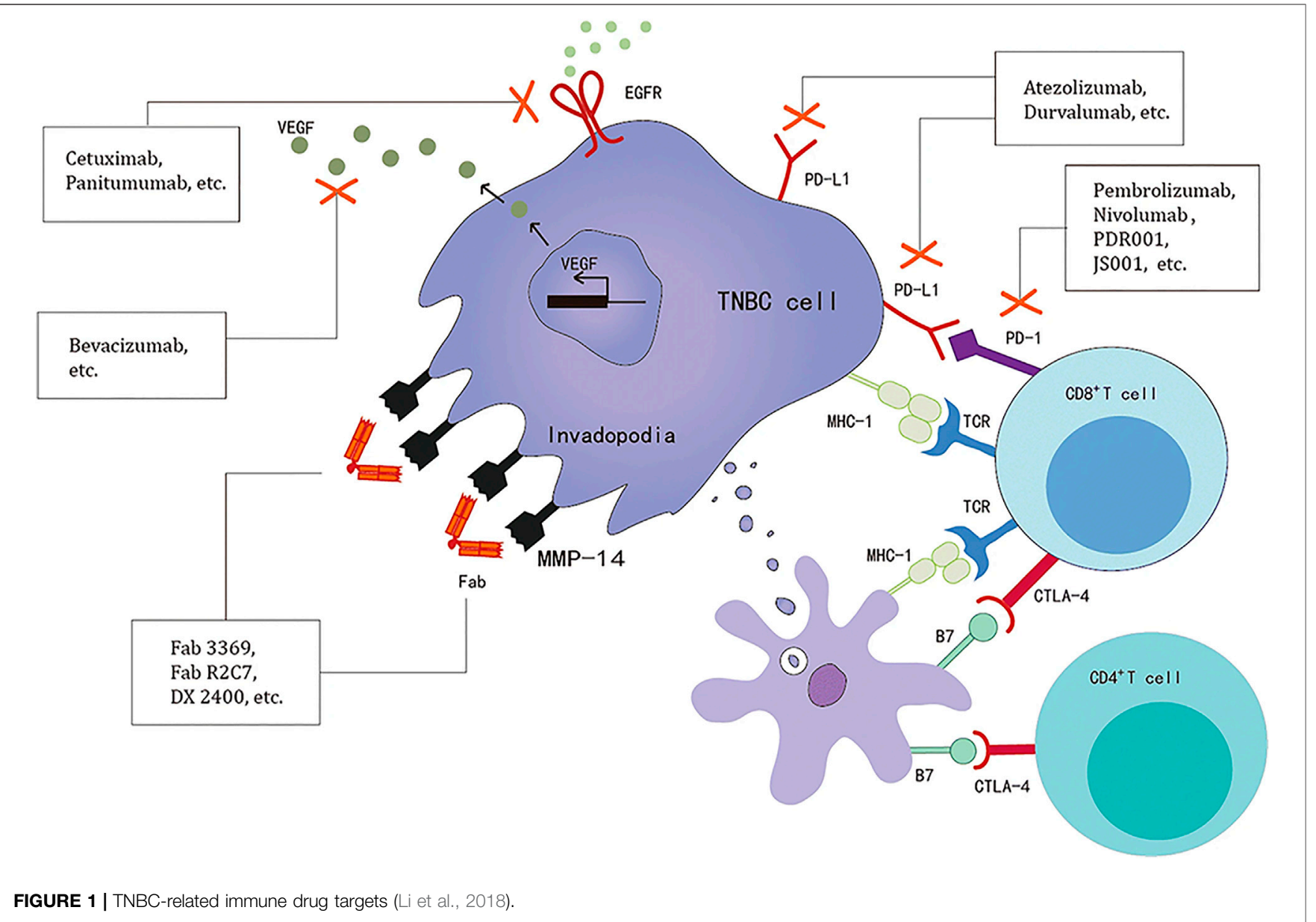

TNBC is a kind of highly malignant cancer. It's evolution and drug resistance remain the greatest challenges to disease treatment. Since targeted therapies are less effective against TNBC, immunotherapy may benefit patients. Immune-related drug targets are currently used in the clinical treatment of TNBC patients (Figure 1) (Li et al., 2018a). Paul Ehrlich, who first proposed the doctrine of immune surveillance in 1909, suggested that abnormal immune function might contribute to the development of tumors (Ehrlich., 1909). The first immune detection site to be used in medical practice was cytotoxic $\mathrm{T}$ lymphocyte-associated antigen-4 (CTLA-4), discovered in 1987 (Brunet et al., 1987). James Allison's group first demonstrated in experiments in mice that the use of CTLA-4 antibodies could enhance immunity and suppress tumor development in 1996 (Leach et al., 1996). Programmed cell death-1 (PD-1) was discovered in 1992, and studies targeting the immune checkpoints CTLA-4, PD-1, and programmed cell deathLigand 1 (PD-L1) have led to breakthroughs in a variety of cancer types. PD-1 inhibitors have brought the treatment of malignant tumors into a new era of immunotherapy (Ishida et al., 1992; Zhang et al., 2021). PD-1, in combination with PD-L1, can transmit inhibitory signals and help tumors undergo immune escape. Approximately $20 \%$ of TNBC express PD-L1 (Mittendorf et al., 2014), targeting PD-L1 therapy in TNBC patients with positive PD-L1 expression was found to prolong the survival of such patients (Romero, 2019).

The database for Traditional Chinese Medicine on ImmunoOncology contains 400 tumor immune targets from different literature and the corresponding 126,972 ligand molecules, demonstrating the active role of traditional Chinese medicine (TCM) in immune function (Liu et al., 2020). TCM works by modulating immune cells in the body, such as $\mathrm{T}$ lymphocytes, bursa dependent lymphocytes, natural killer cells, and macrophages cells, which can exert anti-tumor immune effects (Wang et al., 2020). There are many studies on the combined application of TCM with targeted drugs or immunotherapy, with the main purpose of improving efficacy, reversing drug resistance, reducing adverse effects, and prolonging the survival of patients (Chu et al., 2003; Liu et al., 2019a). Therefore, this paper focuses on the summary of different active ingredients of TCM in immunotherapy for TNBC.

\section{Immune Effect of TCM Containing Alkaloids on TNBC}

Plant alkaloids play an anti-cancer effect in cancer treatment. By regulating immune function, inhibiting angiogenesis, and inducing cell apoptosis (Efferth and Oesch, 2021). Tetrandrine 
has a wide range of antitumor effects and can inhibit MDA-MB231 cell proliferation and induce cellular autophagy by inhibiting phosphatidylinositol-3-kinase (P13K), protein kinase B (AKT), mammalian target of rapamycin (mTOR) pathway (Liu et al., 2016; Guo and Pei, 2019). Reactive oxygen species (ROS) are a class of molecules produced during oxidative stress in the body, which are closely related to tumor immune tolerance and play a key role in immune monitoring (Bailly, 2020; Hu et al., 2021). ROS-triggered small ubiquitin-like modifier (SUMO)-specific protease 3 accumulation is involved in Treg cell-mediated immunosuppression (Yu et al., 2018). In addition to ROS, activation of the Ras, mitogen-activated protein kinase (MAPK) pathway may promote tumor immune evasion in TNBC (Loi et al., 2019). Sinomenine induced apoptosis in MDA-MB-231 cells by upregulating the MAPK pathway and by increasing intracellular ROS production. It also decreased the expression of IL-8, chemokine receptor 2(CXCR2) in MDA-MB231 cells. Inhibited the activation of nuclear factor kappa-B (NF$\kappa \mathrm{B})$ and sonic hedgehog signaling pathways in TNBC lung metastasis. (Li et al., 2014; Song et al., 2018; Zhang et al., 2019).

Berberine increased the release of lactate dehydrogenase in MDA-MB-231 cells in a dose-dependent manner, which led to a significant decrease in the secretion of IL-1 $\alpha$, IL-1 $\beta$, IL-6, and TNF- $\alpha$ at the same time. Synergistic treatment with berberine and lipopolysaccharide significantly reduced the expression of TNF- $\alpha$ and IL- 6 (Zhao et al., 2017; Kim et al., 2018; Lin et al., 2019; Yao et al., 2019; Yao et al., 2019; Zhao and Zhang, 2020). High mobility group box-1(HMGB1) protein is an endogenous member of the proteome called danger-associated molecular pattern that promotes proliferation and survival of a variety of immunosuppressive cells. Synergistic effects of theophylline and berberine induce cell cycle arrest and poly ADP-ribose polymerase (PARP), HMGB1 protein and b-cell lymphoma 2 family-mediated apoptosis in MDA-MB-231 cells (Wild et al., 2012; Hashemi-Niasari et al., 2018).

Cisplatin resistance is associated with breast cancer susceptibility genes. The PARP inhibitor olaparib induces $\mathrm{CD} 8^{+} \mathrm{T}$ cell activation in vivo (Pantelidou et al., 2019; Pettitt et al., 2020). Triptolide downregulates PARP1 levels and inhibits BT549 as well as MDAMB-231 cell growth, mainly by interfering with X-ray repair crosscomplement 1, PAPR1-mediated base excision repair, thereby sensitizing TNBC to cisplatin (Zhang et al., 2019). Both Celastrol and Triptolide inhibit mammosphere formation in MDA-MB-231, BT20 progenitor cells. It inhibited the expression of stem cell marker proteins doublecortin-like kinase 1, aldehyde dehydrogenase, and CD133 (Prominin-1) (Ramamoorthy et al., 2021).

In addition to the above TCM containing alkaloids, such as aconitine, betaine, ephedrine, and evodiamine, which also have antitumor effects (Ma and Wink, 2008; Du et al., 2013; Hyuga et al., 2013; Tan et al., 2020; Zhang et al., 2021), but the immune mechanism of action on TNBC still deserves further investigation.

\section{Immune Effect of TCM Containing Phenolic Compound on TNBC}

During tumor progression, tumor cells continuously interact with the microenvironment and mediate immune tolerance.
Polyphenols, the active ingredients of TCM, can inhabit the tumor microenvironment (Hui and Chen, 2015; Bian et al., 2020). The ability of breast cancer stem cells to self-renew is closely related to disease progression, and high expression of stem cell estrogen receptor alpha-36 (ER-a36) (Deng et al., 2014). Epigallocatechin-3-gallate is a type of catechin extracted from green tea, effectively inhibited the growth of tumor stem, progenitor cells in MDA-MB-231 and MDA-MB-436 cells and reduced the expression of ER- $\alpha 36$ in these cells (Pan et al., 2016). F-Box and WD repeat domain containing 7 (FBXW7) can inhibit tumor development by acting on the tumor microenvironment (Yumimoto et al., 2015). Honokiol downregulates miR-188-5p via FBXW7, c-Myc signaling, enhances the sensitivity of human breast cancer to doxorubicin. Honokiol exerts anti-proliferative activity during cell cycle arrest in G0/G1 phase and inhibits the proliferation of MDA-MB-231 cells by suppressing the c-Src, epidermal growth factor receptor (EGFR)-mediated signaling pathway. However, due to the limited oral bioavailability of honokiol, the use of vitamin E polyethylene glycol succinate in nanocapillary formulations enhances the anti-cancer effect of in situ TNBC (Park et al., 2009; Godugu et al., 2017; Yi et al., 2021). The NF- $\kappa$ B pathway, a key regulator of the immune response, is frequently dysregulated in cancer (Tegowski and Baldwin, 2018). Magnolol significantly inhibited the activity of highly invasive MDA-MB-231 cells and down-regulated the expression of matrix metallopeptidase 9 (MMP-9), as well as the transcriptional activity of NF- $\kappa B$ and the deoxyribonucleic acid (DNA) binding of NF- $\kappa B$ to the MMP-9 promoter (Liu et al., 2013).

The flavonoids found in TCM have a variety of biological properties, including anti-inflammatory and anti-angiogenic properties, play an immune role by influencing immune organs, cellular immunity, non-specific immunity, and immune-related signal transduction pathways. (Casagrande and Darbon, 2001; Bagli et al., 2004; Ullmannova and Popescu, 2007; Maleki et al., 2019). Puerarin inhibited the migration, invasion and adhesion of lipopolysaccharide-stimulated MDA-MB-231 cells by inhibiting the NF- $\kappa \mathrm{B}$ pathway and extracellular regulated protein kinases (ERK) phosphorylation (Liu et al., 2017). However, due to poor water solubility and low bioavailability of puerarin, new puerarin nanoemulsions were developed to induce changes in the immune microenvironment of 4T1 cells, improving the therapeutic efficiency of a-PD-L1 in TNBC models and downregulating intra-tumor ROS (Xu et al., 2020). Licorice flavonoids promote ROS production, increase endogenous and exogenous apoptotic pathways, promote PARP-1 activation in MDA-MB-231 cells, and induce DNA damage. It regulates autophagy and blocks cell growth by inhibiting phosphorylation of AKT and MAPK signaling pathways, regulating the expression of E-cadherin and vimentin (Huang et al., 2019) (-)-Epigallocatechin 3-gallate is a natural polyphenol extracted from green tea, and a series of derivatives were synthesized to improve the pharmacological structure, and all of these compounds were found to exhibit moderate to high cytotoxicity against MDA-MB-231 cells (Crous-Masó et al., 2018).

TCM such as paeonol and curcumin also contain phenolic active ingredients and play an important role in the anti-tumor process (Cai et al., 2014; Hu et al., 2019), which still need to be further explored in the process of immunotherapy for TNBC. 


\section{Immune Effect of Saponins on TNBC}

Saponins have pharmacological activities such as antioxidant, anti-inflammatory, and antitumor. The inhibitory effect of ginseng on breast cancer cell growth is mainly through transcriptional upregulation of the cell cycle protein-dependent kinase inhibitors p21 and p53 (Block and Mead, 2003; AL Shabanah et al., 2016). The combination of ginsenoside panaxatriol with paclitaxel inhibited the activation of interleukin-1 receptor-associated kinase 1(IRAK1), NF- $\mathrm{BB}$ and ERK1/2, leading to the inhibition of inflammatory factors, and cancer stem cell-related genes expression was downregulated and also inhibited the invasive ability of MB231-PR (paclitaxelresistant) cells, reducing stem cell properties and resensitizing TNBC paclitaxel-resistant cells to paclitaxel by inhibiting the IRAK1/NF- $\kappa B$ and ERK pathways (Wang et al., 2020). In contrast, ginsenoside Rg1 induces apoptosis through ROS production and inhibits the development of triple negative breast cancer cells (Chu et al., 2020).

Ginsenoside Rh2 induces apoptosis, reverses abnormal differentiation of tumor cells, and resists tumor metastasis, and can be used in combination with chemotherapeutic drugs to increase the effectiveness and reduce the toxicity. Biochanin A combined with ginsenoside Rh2 has a synergistic effect on the proliferation of MDA-MB-231 and MCF-7 cells (Ren et al., 2018). Ginsenoside $\mathrm{Rg} 3$ in combination with paclitaxel treatment inhibited NF-kB activation, decreased NF-kB p65 and B-cell lymphoma-2 (Bcl-2) protein expression, and increased $\mathrm{Bcl} 2$ associated $\mathrm{X}$ and Caspase-3 protein expression, thus promoting the toxicity of paclitaxel on MDA-MB-231, MDAMB453, and BT-549 cells (Yuan et al., 2017). After analysis using The Cancer Genome Atlas database identified a role for C-X-C motif chemokine ligand 12 (CXCL12), C-X-C motif chemokine receptor 4 (CXCR4) signaling pathway in oncogenic $\mathrm{CD}^{+} \mathrm{T}$ cells from human breast cancer, CXCR4 inhibition could enhance the efficacy of immunotherapy in the treatment of metastatic breast cancer (Chen et al., 2019). At doses without significant cytotoxicity, ginsenoside $\mathrm{Rg} 3$ treatment resulted in weaker CXCR4 staining in MDA-MB-231 cells, reduced the number of cells migrating during CXCL12-induced chemotaxis, and significantly reduced the number of CD44 high $/ C D 24^{\text {low }}$ in MDA-MB-231 cells with therapeutic potential for targeting breast cancer stem cells, possibly through classical mitochondria-dependent caspase activation to induce apoptosis in MDA-MB-231 cells (Chen et al., 2011; Kim et al., 2013; Oh et al., 2019).

Murine double minute2 (MDM2) controls the stability of STAT5 in $\mathrm{CD}^{+} \mathrm{T}$ cells and targeting p53-MDM2 interactions is essential for effective antitumor immunity. Polyphyllin D can inhibit MDA-MB-231 cell proliferation by decreasing the expression levels of MDM2, murine double minute $\mathrm{x}$, and mutant p53 and inducing cell cycle arrest by upregulating the expression of MDM2 downstream proteins p21 and p27 (Kong et al., 2016; Zhou et al., 2021). RELT-like protein 2 (Rell2) is a direct target of mircoRNA-18a, and polyphyllin VI increased Rell 2 expression and impaired the viability of $4 \mathrm{~T} 1$ and MDA-MB231 cells (Wang et al., 2019). Timosaponin AIII, a steroidal saponin, triggers DNA damage in breast cancer, activates the ataxia telangiectasia mutated, cell cycle checkpoint kinase 2 and p38 MAPK pathways, which in turn induces $\mathrm{G} 2 / \mathrm{M}$ phase block and MDA-MB-231 apoptosis, and downregulates cell division cycle B1, cell division cycle 2, and cell division cycle 25C. Inhibition of ERK activation through sustained hepatocyte growth factor-induced MDA-MB-231 cell invasion (Tsai et al., 2013; Zhang et al., 2021). Ophiopogonin D significantly inhibits TNBC cell growth and metastasis in vitro, mediated in part by inhibition of the integrin subunit beta 1 , focal adhesion kinase, Src, AKT, $\beta$-catenin signaling pathway (Zhu et al., 2020).

\section{Immune Effect of Polysaccharides TCM on TNBC}

Polysaccharides isolated from TCM have immunomodulatory and antitumor effects and play an important role in immunosuppression (Chen et al., 2006; Liu et al., 2018). Based on the basis of network-based pharmacology it was determined that astragalus polysaccharide may interfere with the invasion and proliferation of MDA-MB-231 cells by inhibiting PI3KCG/ $\mathrm{AKT} / \mathrm{Bcl} 2$ pathway expression and can promote apoptosis. In vitro experiments it confirmed that astragalus polysaccharide inhibits TNBC symptoms in a dose-dependent manner (Liu et al., 2019b). Huaier polysaccharide inhibited the stem celllike characteristics of MDA-MB-231, MDA-MB-453 and Hs578T cells in vitro and in vivo, partly through the estrogen receptor a-36 signaling pathway ( $\mathrm{Hu}$ et al., 2019). Fucoidan inhibits MAPK and $\mathrm{P} 13 \mathrm{~K}$ activation, suppresses activating protein-1 and NF- $\kappa \mathrm{B}$ signaling, downregulates pro-angiogenic factor expression in TNBC cells, exhibits anti-ataxia telangiectasia mutated, cell cycle checkpoint kinase 2 proliferative activity against MDA-MB-231 and HCC1806 cells, and effectively reduces migration and invasion (Hsu et al., 2013; Hsu et al., 2020). Cordyceps polysaccharides effectively inhibited MDA-MB-231 cell metastasis and restored drug sensitivity in topotecan-resistant cells by downregulating the transforming growth factor- $\beta$ signaling pathway and EMT program (Lin et al., 2016).

Shiitake mushroom polysaccharide, Ganoderma lucidum polysaccharide, polysaccharides from the roots of platycodon grandiflorum, Safflower polysaccharide and Ginseng polysaccharide all have strong anti-tumor activity (Chihara et al., 1969; Ando et al., 2002; Gao et al., 2003; Yoon et al., 2003). However, studies in TNBC are still relatively few and the immune mechanism of action is unclear, which deserves further development.

\section{Immune Effect of Other TCM Ingredients on TNBC}

In addition to the aforementioned drugs, tubeimu also exhibited in vitro inhibition of TNBC cell migration and invasion without significant toxic side effects (Wang et al., 2018). Cantharidin reverses the metastasis of MDA-MB-231 cells by inhibiting pyruvate kinase isozyme type M2 nuclear translocation and disrupting the glucose transporter 1, pyruvate kinase isozyme type M2 glycolytic cycle, leading to the conversion of aerobic 
TABLE 1 | Role of TCM in TNBC.

\begin{tabular}{|c|c|c|c|}
\hline Compound & $\begin{array}{l}\text { Detailed activity/mechanism of } \\
\text { action }\end{array}$ & Application & References \\
\hline \multirow[t]{2}{*}{ Sinomenine } & $\begin{array}{l}\text { Reduced human IL-8 mRNA expression in MDA-MB-231 cells; } \\
\text { downregulated CXCR1. }\end{array}$ & $\begin{array}{l}\text { In vivo and } \\
\text { in vitro }\end{array}$ & Zhang et al. (2019) \\
\hline & $\begin{array}{l}\text { ROS-dependent and non-dependent pathways; upregulated the } \\
\text { expression of MAPKs. }\end{array}$ & $\begin{array}{l}\text { In vivo and } \\
\text { in vitro }\end{array}$ & Li et al. (2014) \\
\hline Berberine & $\begin{array}{l}\text { Inhibited IL-1 } \alpha, \mathrm{IL}-1 \beta, \mathrm{IL}-6 \text {, TNF- } \alpha \text { expression; downregulated EGFR } \\
\text { protein expression }\end{array}$ & $\begin{array}{l}\text { In vivo and } \\
\text { in vitro }\end{array}$ & Zhao and Zhang, (2020) \\
\hline Theophylline & $\begin{array}{l}\text { Reduced extracellular levels of HMGB1 protein and downregulated } \\
\text { HMGB1 and MMP-9 mRNA expression }\end{array}$ & In vitro & $\begin{array}{l}\text { (Wild et al., 2012, Hashemi-Niasari } \\
\text { et al. (2018) }\end{array}$ \\
\hline \multirow[t]{3}{*}{ Honokiol } & $\begin{array}{l}\text { Sensitized doxorubicin-resistant breast cancer cells to doxorubicin- } \\
\text { induced apoptosis }\end{array}$ & In vitro & Yi et al. (2021) \\
\hline & Increased solubility of honokiol in nano-micellar formulations & $\begin{array}{l}\text { In vitro and in } \\
\text { vivo }\end{array}$ & Godugu et al. (2017) \\
\hline & $\begin{array}{l}\text { Downregulated the expression and phosphorylation of c-Src, EGFR and } \\
\text { AKT; inactivated mTOR and its downstream signal molecules }\end{array}$ & In vitro & Park et al. (2009) \\
\hline \multirow[t]{2}{*}{ Puerarin } & Abrogated the NF-kB; inhibited phosphorylation of p65 and IkBa & In vitro & Liu et al. (2017) \\
\hline & Downregulated ROS production in the activated myofibroblast & $\begin{array}{l}\text { In vivo and } \\
\text { in vitro }\end{array}$ & Xu et al. (2020) \\
\hline Licorice flavonoids & $\begin{array}{l}\text { Reduced MAPK and AKT signaling, suppressed MDA-MB-231 cell } \\
\text { migration and invasion }\end{array}$ & In vitro & Huang et al. (2019) \\
\hline (-)-Epigallocatechin 3-gallate & $\begin{array}{l}\text { Reduced the expression of ER-a36 in MDA-MB-231 and MDA-MB-436 } \\
\text { cells }\end{array}$ & - & Pan et al. (2016) \\
\hline Huaier polysaccharide & $\begin{array}{l}\text { Reduced ER } \alpha-36 \text { experssion; attenuatted ER } \alpha-36 \text {-mediated activation of } \\
\text { ER } \beta / \alpha \text {-catenin signaling }\end{array}$ & $\begin{array}{l}\text { In vivo and } \\
\text { in vitro }\end{array}$ & Hu et al. (2019) \\
\hline Ginsenoside panaxatriol & $\begin{array}{l}\text { Resensitized TNBC paclitaxel resistant cells to pentatonix by inhibiting the } \\
\text { IRAK1/NF- } \mathrm{BB} \text { and ERK pathways }\end{array}$ & In vitro & Wang et al. (2020) \\
\hline Ginsenoside Rh2 & $\begin{array}{l}\text { Upregulated p-p53, p-p38, and phospho-ASK1 proteins, downregulated } \\
\text { levels of TNF receptor associated factor } 2\end{array}$ & In vitro & Ren et al. (2018) \\
\hline Ginsenoside Rg3 & Regulated Bax/Bcl-2 expression on TNBC by inhibited NF-kB signaling & $\begin{array}{l}\text { In vivo and } \\
\text { in vitro }\end{array}$ & Yuan et al. (2017) \\
\hline Polyphyllin VI & $\begin{array}{l}\text { Inhibited the metastatic potential of } 4 \mathrm{~T} 1 \text { and MDA-MB-231 cells; } \\
\text { attenuated the migration of miR-18a mimic or Rell2 siRNA-enhanced } \\
\text { MDA-MB-231 cells }\end{array}$ & $\begin{array}{l}\text { In vivo and } \\
\text { in vitro }\end{array}$ & Wang et al. (2019) \\
\hline \multirow[t]{2}{*}{ Timosaponin Alll } & $\begin{array}{l}\text { Activated ATM/Chk2 and p38 pathways upregulated phospho-histone } \\
\text { H2A.X and p-p38 levels }\end{array}$ & $\begin{array}{l}\text { In vivo and } \\
\text { in vitro }\end{array}$ & Zhang et al. (2021) \\
\hline & $\begin{array}{l}\text { Inhibited the activation of cytosolic activated transcription factor 2; } \\
\text { downregulated cyclo-oxygenase-2 and MMP-9 transcription }\end{array}$ & In vitro & Tsai et al. (2013) \\
\hline Fucoidan & $\begin{array}{l}\text { Inhibited TNBC invasiveness and pro-angiogenesis; regulated EMT by } \\
\text { modulated TGFR/Smad dependent signaling }\end{array}$ & - & Hsu et al. (2020) \\
\hline Cordyceps polysaccharides & $\begin{array}{l}\text { Inhibited breast cancer metastasis and restored drug sensitivity in drug- } \\
\text { resistant cells by down-regulating the transforming growth factor- } \beta \\
\text { signaling pathway and EMT program }\end{array}$ & $\begin{array}{l}\text { In vivo and } \\
\text { in vitro }\end{array}$ & Lin et al. (2016) \\
\hline Bufalin & $\begin{array}{l}\text { Inhibited human breast cancer tumorigenesis by inducing cell death } \\
\text { through the ROS-mediated RIP1/RIP3/PARP-1 pathways }\end{array}$ & $\begin{array}{l}\text { In vivo and } \\
\text { in vitro }\end{array}$ & Li et al. (2018) \\
\hline Arctigenin & $\begin{array}{l}\text { Enhanced DOX-induced DNA damage, decreased the phosphorylation of } \\
\text { signal STAT3 and the expressions of RAD51 and survivin }\end{array}$ & In vitro & Lee et al. (2020) \\
\hline $\begin{array}{l}\text { Exaction of Citrus hystrix DC (Citronellol } \\
\text { and Citronellal) }\end{array}$ & $\begin{array}{l}\text { Induced apoptosis in MDA-MB-231 cells through inhibition of anti- } \\
\text { apoptotic Bcl-2 expression, leading to activation of the caspase-3- } \\
\text { dependent pathway }\end{array}$ & In vitro & Ho et al. (2020) \\
\hline Rhubarb acid derivatives & $\begin{array}{l}\text { Induced apoptosis, G2/M phase cell cycle arrest and oxidative stress in } \\
\text { MDA-MB231 cells; activated pro-apoptotic JNK1; downregulated anti- } \\
\text { apoptotic ERK1 and anti-apoptotic bcl-2; increased the bax/bcl-2 ratio } \\
\text { and initiated the mitochondrial apoptosis pathway }\end{array}$ & In vitro & Li et al. (2020) \\
\hline
\end{tabular}

glycolysis to oxidation (Pan et al., 2019). More toxic drugs may limit their use in vivo and improve in vivo safety by developing a novel drug, a-amanitin-conjugated trastuzumab, which kills tumor cells while inducing immunogenic cell death, using the HER2 antibody trastuzumab coupled to a-amanitin, and cells containing $17 \mathrm{p}$ deletion, which are expressed at low levels of HER2 (Li et al., 2021). Bufalin increased the expression of necrosis mediators threonine kinase 1 and threonine kinase3, induced MDA-MB-231 cell death and inhibited the growth of both human breast cancer MCF-7 and MDA-MB-231 cells through the reactive oxygen species-mediated RIP1/RIP3/ PARP-1 pathway (Li et al., 2018b).

Arctigenin induces prolonged p21 expression and p38mediated apoptosis-inducing factor-dependent cell death, which enhanced the toxicity of adriamycin in human breast cancer cells. (Lee et al., 2020). Three triterpenes were isolated 
from cactus, of which compound $\mathrm{d} 2$ was identified as betulinic acid, and treatment of MDA-MB-231 cells with betulinic acidrich cactus resulted in activation of c-Jun $\mathrm{N}$-terminal kinase as well as downregulation of ERK1 (Foo et al., 2016). Citrus hystrix DC extract and its compounds citronellol and citronellal induce apoptosis in MDA-MB-231 by inhibiting the anti-apoptotic protein $\mathrm{Bcl}-2$, leading to activation of the pro-apoptotic $\mathrm{Bcl} 2$ associated $\mathrm{X}$ protein and inducing a downstream cystatindependent apoptotic pathway by activating cystatin-3 protein (Ho et al., 2020). Rhubarb acid derivatives are new anthraquinones that downregulate Racl expression and maybe small molecule inhibitors of Rac1 (Li et al., 2020). Gambogic acid significantly inhibits viability and increases apoptosis of paclitaxel-resistant MDA-MB-231 cells through activation of the sonic hedgehog signaling pathway (Wang et al., 2019). In a word, we have summarized some key ingredients from the above in table 1 .

\section{CONCLUSION}

TCM is widely used as an adjunct method in tumor treatment. Numerous studies have demonstrated that TCM exerts its immune effects through the following pathways, enhanced immune response, reduced immune tolerance, and suppressed tumor immunity. In addition to regulating tumor microenvironment-related factors, such as interleukins, interferons, tumor necrosis factors, chemokines, and growth factors, TCM treatments can also regulate immune cells by restoring the antigen expression function of dendritic cells, enhancement of natural killer cell activity, and inhibition of associated fibroblasts (Takei et al., 2004; Mu et al., 2016; Wang et al., 2020). The above study provides a new therapeutic option for TCM immunotherapy against TNBC.

\section{REFERENCES}

Al Shabanah, O. A., Alotaibi, M. R., Al Rejaie, S. S., Alhoshani, A. R., Almutairi, M. M., Alshammari, M. A., et al. (2016). Hafez MM. Inhibitory Effect of Ginseng on Breast Cancer Cell Line Growth via Up-Regulation of Cyclin Dependent Kinase Inhibitor, P21 and P53. Asian Pac. J. Cancer Prev. 17 (11), 4965-4971. doi:10.22034/APJCP.2016.17.11.4965

Ando, I., Tsukumo, Y., Wakabayashi, T., Akashi, S., Miyake, K., Kataoka, T., et al. (2002). Safflower Polysaccharides Activate the Transcription Factor NF-Kappa B via Toll-like Receptor 4 and Induce Cytokine Production by Macrophages. Int. Immunopharmacol 2 (8), 1155-1162. doi:10.1016/s1567-5769(02)00076-0

Bagli, E., Stefaniotou, M., Morbidelli, L., Ziche, M., Psillas, K., Murphy, C., et al. (2004). Luteolin Inhibits Vascular Endothelial Growth Factor-Induced Angiogenesis; Inhibition of Endothelial Cell Survival and Proliferation by Targeting Phosphatidylinositol 3'-kinase Activity. Cancer Res. 64 (21), 7936-7946. doi:10.1158/0008-5472.CAN-03-3104

Bailly, C. (2020). Regulation of PD-L1 Expression on Cancer Cells with ROSModulating Drugs. Life Sci. 246, 117403. doi:10.1016/j.lfs.2020.117403

Bian, Y., Wei, J., Zhao, C., and Li, G. (2020). Natural Polyphenols Targeting Senescence: A Novel Prevention and Therapy Strategy for Cancer. Int. J. Mol. Sci. 21 (2), 684. doi:10.3390/ijms21020684

Block, K. I., and Mead, M. N. (2003). Immune System Effects of Echinacea, Ginseng, and astragalus: a Review. Integr. Cancer Ther. 2 (3), 247-267. doi:10.1177/1534735403256419
This paper mainly reviews the immunomodulatory mechanism of different active ingredients of TCM on TNBC. But research on the effects of TCM on immune responses to TNBC is rather scarce. TCM immunomodulatory effects are less studied and there is little information on immune targets. The majority of the studies are focused on immune factor expression. In TCM treatments with demonstrated toxic side effects, exploring how these can be reduced while increasing immune activation against tumors, is worth further investigation. The mechanisms of TCM synergistic radiotherapy drugs on TNBC are still unclear, and the synergistic immune mechanism of multiple drugs still needs to be explored.

\section{AUTHOR CONTRIBUTIONS}

$\mathrm{WZ}$ prepared the manuscript. $\mathrm{WZ}$ and $\mathrm{ZZ}$ worked together on the idea, $Z Z$ reviewed the draft and provided important information, YL and JL reviewed the draft, and ZC and DQ reviewed the draft. All authors approved the final version of this manuscript for submission.

\section{FUNDING}

This work was supported by the National Nature Science Foundation of China (No. 21775061,81974555), Shandong Provincial Key Research and Development Program (2019GSF108253), Open Funds of State Key Laboratory of ChemoBiosensing and Chemometrics (2019016), Science Foundation of Innovative Research Teams of Accurate Disease Identification and Targeted Therapy (22202105). Details of all funding sources should be provided, including grant numbers if applicable.

Brunet, J. F., Denizot, F., Luciani, M. F., Roux-Dosseto, M., Suzan, M., Mattei, M. G., et al. (1987). A New Member of the Immunoglobulin Superfamily--CTLA-4. Nature 328 (6127), 267-270. doi:10.1038/328267a0

Cai, J., Chen, S., Zhang, W., Hu, S., Lu, J., Xing, J., et al. (2014). Paeonol Reverses Paclitaxel Resistance in Human Breast Cancer Cells by Regulating the Expression of Transgelin 2. Phytomedicine 21 (7), 984-991. doi:10.1016/ j.phymed.2014.02.012

Casagrande, F., and Darbon, J. M. (2001). Effects of Structurally Related Flavonoids on Cell Cycle Progression of Human Melanoma Cells: Regulation of Cyclindependent Kinases CDK2 and CDK1. Biochem. Pharmacol. 61 (10), 1205-1215. doi:10.1016/s0006-2952(01)00583-4

Chen, I. X., Chauhan, V. P., Posada, J., Ng, M. R., Wu, M. W., Adstamongkonkul, P., et al. (2019). Blocking CXCR4 Alleviates Desmoplasia, Increases T-Lymphocyte Infiltration, and Improves Immunotherapy in Metastatic Breast Cancer. Proc. Natl. Acad. Sci. U.S.A. 116 (10), 4558-4566. doi:10.1073/pnas.1815515116

Chen, X. P., Qian, L. L., Jiang, H., and Chen, J. H. (2011). Ginsenoside Rg3 Inhibits CXCR4 Expression and Related Migrations in a Breast Cancer Cell Line. Int. J. Clin. Oncol. 16 (5), 519-523. doi:10.1007/s10147-011-0222-6

Chen, X., Yang, L., Howard, O. M., and Oppenheim, J. J. (2006). Dendritic Cells as a Pharmacological Target of Traditional Chinese Medicine. Cell Mol Immunol 3 (6), 401-410.

Chihara, G., Maeda, Y., Hamuro, J., Sasaki, T., and Fukuoka, F. (1969). Inhibition of Mouse Sarcoma 180 by Polysaccharides from Lentinus Edodes (Berk.) Sing. Nature 222 (5194), 687-688. doi:10.1038/222687a0 
Chu, K. C., Lamar, C. A., and Freeman, H. P. (2003). Racial Disparities in Breast Carcinoma Survival Rates: Seperating Factors that Affect Diagnosis from Factors that Affect Treatment. Cancer 97 (11), 2853-2860. doi:10.1002/ cncr.11411

Chu, Y., Zhang, W., Kanimozhi, G., Brindha, G. R., and Tian, D. (2020). Ginsenoside Rg1 Induces Apoptotic Cell Death in Triple-Negative Breast Cancer Cell Lines and Prevents Carcinogen-Induced Breast Tumorigenesis in Sprague Dawley Rats. Evid. Based Complement. Alternat Med. 2020, 8886955. doi:10.1155/2020/8886955

Coates, A. S., Winer, E. P., Goldhirsch, A., Gelber, R. D., Gnant, M., PiccartGebhart, M., et al. (2015). Tailoring Therapies-Iimproving the Management of Early Breast Cancer: St Gallen International Expert Consensus on the Primary Therapy of Early Breast Cancer 2015. Ann. Oncol. 26 (8), 1533-1546. doi:10.1093/annonc/mdv221

Crous-Masó, J., Palomeras, S., Relat, J., Camó, C., Martínez-Garza, Ú., Planas, M., et al. (2018). (-)-Epigallocatechin 3-Gallate Synthetic Analogues Inhibit Fatty Acid Synthase and Show Anticancer Activity in Triple Negative Breast Cancer. Molecules 23 (5), 1160. doi:10.3390/molecules 23051160

Deng, H., Zhang, X. T., Wang, M. L., Zheng, H. Y., Liu, L. J., and Wang, Z. Y. (2014). ER-a36-mediated Rapid Estrogen Signaling Positively Regulates ERPositive Breast Cancer Stem/progenitor Cells. PLoS One 9 (2), e88034. doi:10.1371/journal.pone.0088034

Du, J., Wang, X. F., Zhou, Q. M., Zhang, T. L., Lu, Y. Y., Zhang, H., et al. (2013). Evodiamine Induces Apoptosis and Inhibits Metastasis in MDA-MB-231 Human Breast Cancer Cells In Vitro and In Vivo. Oncol. Rep. 30 (2), 685-694. doi:10.3892/or.2013.2498

Efferth, T., and Oesch, F. (2021). Repurposing of Plant Alkaloids for Cancer Therapy: Pharmacology and Toxicology. Semin. Cancer Biol. 68, 143-163. doi:10.1016/j.semcancer.2019

Ehrlich, P. (1909). Ueber den jetzigen stand der Karzinomforschung. Ned.Tijdschr 5, 273-290.

Foo, J. B., Saiful Yazan, L., Tor, Y. S., Wibowo, A., Ismail, N., Armania, N., et al. (2016). Dillenia suffruticosa Dichloromethane Root Extract Induced Apoptosis towards MDA-MB-231 Triple-Negative Breast Cancer Cells. J. Ethnopharmacol 187, 195-204. doi:10.1016/j.jep.2016.04.048

Gao, Y., Zhou, S., Jiang, W., Huang, M., and Dai, X. (2003). Effects of Ganopoly (A Ganoderma Lucidum Polysaccharide Extract) on the Immune Functions in Advanced-Stage Cancer Patients. Immunol. Invest. 32 (3), 201-215. doi:10.1081/imm-120022979

Godugu, C., Doddapaneni, R., and Singh, M. (2017). Honokiol Nanomicellar Formulation Produced Increased Oral Bioavailability and Anticancer Effects in Triple Negative Breast Cancer (TNBC). Colloids Surf. B Biointerfaces 153, 208-219. doi:10.1016/j.colsurfb.2017.01.038

Goto, W., Kashiwagi, S., Takada, K., Asano, Y., Takahashi, K., Fujita, H., et al. (2018). Significance of Intrinsic Breast Cancer Subtypes on the Long-Term Prognosis after Neoadjuvant Chemotherapy. J. Transl Med. 16 (1), 307. doi:10.1186/s12967-018-1679-0

Guo, Y., and Pei, X. (2019). Tetrandrine-Induced Autophagy in MDA-MB231 Triple-Negative Breast Cancer Cell through the Inhibition of PI3K/ AKT/mTOR Signaling. Evid. Based Complement. Alternat Med., 7517431. doi:10.1155/2019/7517431

Hashemi-Niasari, F., Rabbani-Chadegani, A., Razmi, M., and Fallah, S. (2018). Synergy of Theophylline Reduces Necrotic Effect of Berberine, Induces Cell Cycle Arrest and PARP, HMGB1, Bcl-2 Family Mediated Apoptosis in MDAMB-231 Breast Cancer Cells. Biomed. Pharmacother. 106, 858-867. doi:10.1016/j.biopha.2018.07.019

Ho, Y., Suphrom, N., Daowtak, K., Potup, P., Thongsri, Y., and Usuwanthim, K. (2020). Anticancer Effect of Citrus hystrix DC. Leaf Extract and its Bioactive Constituents Citronellol and, Citronellal on the Triple Negative Breast Cancer MDA-MB-231 Cell Line. Pharmaceuticals (Basel) 13 (12), 476. doi:10.3390/ ph13120476

Hsu, H. Y., Lin, T. Y., Hwang, P. A., Tseng, L. M., Chen, R. H., Tsao, S. M., et al. (2013). Fucoidan Induces Changes in the Epithelial to Mesenchymal Transition and Decreases Metastasis by Enhancing Ubiquitin-dependent TGF $\beta$ Receptor Degradation in Breast Cancer. Carcinogenesis 34 (4), 874-884. doi:10.1093/ carcin/bgs396

Hsu, W. J., Lin, M. H., Kuo, T. C., Chou, C. M., Mi, F. L., Cheng, C. H., et al. (2020). Fucoidan from Laminaria Japonica Exerts Antitumor Effects on Angiogenesis and Micrometastasis in Triple-Negative Breast Cancer Cells. Int. J. Biol. Macromol 149, 600-608. doi:10.1016/j.ijbiomac.2020.01.256

Hu, B., Yan, W., Wang, M., Cui, X., Hu, Y., Chen, Q., et al. (2019). Huaier Polysaccharide Inhibits the Stem-like Characteristics of ERa-36high Triple Negative Breast Cancer Cells via Inactivation of the ERa-36 Signaling Pathway. Int. J. Biol. Sci. 15 (7), 1358-1367. doi:10.7150/ijbs.27360

Hu, C., Li, M., Guo, T., Wang, S., Huang, W., Yang, K., et al. (2019). Anti-metastasis Activity of Curcumin against Breast Cancer via the Inhibition of Stem Cell-like Properties and EMT. Phytomedicine 58, 152740. doi:10.1016/ j.phymed.2018.11.001

Hu, Z., Teng, X. L., Zhang, T., Yu, X., Ding, R., Yi, J., et al. (2021). SENP3 Senses Oxidative Stress to Facilitate STING-dependent Dendritic Cell Antitumor Function. Mol. Cel 81 (5), 940-952. doi:10.1016/j.molcel.2020.12.024

Huang, W. C., Su, H. H., Fang, L. W., Wu, S. J., and Liou, C. J. (2019). Licochalcone A Inhibits Cellular Motility by Suppressing E-Cadherin and MAPK Signaling in Breast Cancer. Cells 8 (3), 218. doi:10.3390/cells8030218

Hui, L., and Chen, Y. (2015). Tumor Microenvironment: Sanctuary of the Devil. Cancer Lett. 368 (1), 7-13. doi:10.1016/j.canlet.2015.07.039

Hyuga, S., Hyuga, M., Yoshimura, M., Amakura, Y., Goda, Y., and Hanawa, T. (2013). Herbacetin, a Constituent of Ephedrae Herba, Suppresses the HGFInduced Motility of Human Breast Cancer MDA-MB-231 Cells by Inhibiting C-Met and Akt Phosphorylation. Planta Med. 79 (16), 1525-1530. doi:10.1055/ s-0033-1350899

Ishida, Y., Agata, Y., Shibahara, K., and Honjo, T. (1992). Induced Expression of PD-1, a Novel Member of the Immunoglobulin Gene Superfamily, upon Programmed Cell Death. EMBO J. 11 (11), 3887-3895.

Kim, B. M., Kim, D. H., Park, J. H., Na, H. K., and Surh, Y. J. (2013). Ginsenoside Rg3 Induces Apoptosis of Human Breast Cancer (MDA-MB-231) Cells. J. Cancer Prev. 18 (2), 177-185. doi:10.15430/jcp.2013.18.2.177

Kim, S., You, D., Jeong, Y., Yu, J., Kim, S. W., Nam, S. J., et al. (2018). Berberine Down-Regulates IL-8 Expression through Inhibition of the EGFR/MEK/ERK Pathway in Triple-Negative Breast Cancer Cells. Phytomedicine 50, 43-49. doi:10.1016/j.phymed

Kong, Y., Lu, Z. L., Wang, J. J., Zhou, R., Guo, J., Liu, J., et al. (2016). Platycodin D, a Metabolite of Platycodin Grandiflorum, Inhibits Highly Metastatic MDA-MB231 Breast Cancer Growth In Vitro and In Vivo by Targeting the MDM2 Oncogene. Oncol. Rep. 36 (3), 1447-1456. doi:10.3892/or.2016.4935

Leach, D. R., Krummel, M. F., and Allison, J. P. (1996). Enhancement of Antitumor Immunity by CTLA-4 Blockade. Science 271 (5256), 1734-1736. doi:10.1126/ science.271.5256.1734

Lee, K. S., Lee, M. G., Kwon, Y. S., and Nam, K. S. (2020). Arctigenin Enhances the Cytotoxic Effect of Doxorubicin in MDA-MB-231 Breast Cancer Cells. Int. J. Mol. Sci. 21 (8), 2997. doi:10.3390/ijms21082997

Li, X., Liu, Y., Zhao, Y., Tian, W., Zhai, L., Pang, H., et al. (2020). Rhein Derivative 4F Inhibits the Malignant Phenotype of Breast Cancer by Downregulating Rac1 Protein. Front. Pharmacol. 11, 754. doi:10.3389/fphar.2020.00754

Li, X., Wang, K., Ren, Y., Zhang, L., Tang, X. J., Zhang, H. M., et al. (2014). MAPK Signaling Mediates Sinomenine Hydrochloride-Induced Human Breast Cancer Cell Death via Both Reactive Oxygen Species-dependent and -independent Pathways: an In Vitro and In Vivo Study. Cell Death Dis 5 (7), e1356. doi:10.1038/cddis.2014.321

Li, Y., Sun, Y., Kulke, M., Hechler, T., Van der Jeught, K., Dong, T., et al. (2021). Targeted Immunotherapy for HER2-Low Breast Cancer with 17p Loss. Sci. Transl Med. 13 (580), eabc6894. doi:10.1126/scitranslmed.abc6894

Li, Y., Tian, X., Liu, X., and Gong, P. (2018b). Bufalin Inhibits Human Breast Cancer Tumorigenesis by Inducing Cell Death through the ROS-Mediated RIP1/RIP3/PARP-1 Pathways. Carcinogenesis 39 (5), 700-707. doi:10.1093/ carcin/bgy039

Li, Z., Qiu, Y., Lu, W., Jiang, Y., and Wang, J. (2018a). Immunotherapeutic Interventions of Triple Negative Breast Cancer. J. Transl Med. 16 (1), 147. doi:10.1186/s12967-018-1514-7

Lin, S., Lyu, X., Yu, J., Sun, L., Du, D., Lai, Y., et al. (2016). MHP-1 Inhibits Cancer Metastasis and Restores Topotecan Sensitivity via Regulating Epithelial-Mesenchymal Transition and TGF- $\beta$ Signaling in Human Breast Cancer Cells. Phytomedicine 1523 (10), 1053-1063. doi:10.1016/ j.phymed.2016.06.013

Lin, Y. S., Chiu, Y. C., Tsai, Y. H., Tsai, Y. F., Wang, J. Y., Tseng, L. M., et al. (2019). Different Mechanisms Involved in the Berberine-Induced Antiproliferation 
Effects in Triple-Negative Breast Cancer Cell Lines. J. Cel Biochem 120 (8), 13531-13544. doi:10.1002/jcb.28628

Liu, C., Wang, K., Zhuang, J., Gao, C., Li, H., Liu, L., et al. (2019b). The Modulatory Properties of Astragalus Membranaceus Treatment on Triple-Negative Breast Cancer, an Integrated Pharmacological Method. Front. Pharmacol. 10, 1171. doi:10.3389/fphar.2019.01171

Liu, N., Dong, Z., Zhu, X., Xu, H., and Zhao, Z. (2018). Characterization and Protective Effect of Polygonatum Sibiricum Polysaccharide against Cyclophosphamide-Induced Immunosuppression in Balb/c Mice. Int. J. Biol. Macromol 107 (Pt A), 796-802. doi:10.1016/j.ijbiomac.2017.09.051

Liu, T., Liu, X., and Li, W. (2016). Tetrandrine, a Chinese Plant-Derived Alkaloid, Is a Potential Candidate for Cancer Chemotherapy. Oncotarget 7 (26), 40800-40815. doi:10.18632/oncotarget.8315

Liu, X., Li, M., Wang, X., Dang, Z., Yu, L., Wang, X., et al. (2019a). Effects of Adjuvant Traditional Chinese Medicine Therapy on Long-Term Survival in Patients with Hepatocellular Carcinoma. Phytomedicine 62, 152930. doi:10.1016/j.phymed.2019.152930

Liu, X., Zhao, W., Wang, W., Lin, S., and Yang, L. (2017). Puerarin Suppresses LPSInduced Breast Cancer Cell Migration, Invasion and Adhesion by Blockage NF$\mathrm{Kb}$ and Erk Pathway. Biomed. Pharmacother. 92, 429-436. doi:10.1016/ j.biopha.2017.05.102

Liu, Y., Cao, W., Zhang, B., Liu, Y. Q., Wang, Z. Y., Wu, Y. P., et al. (2013). The Natural Compound Magnolol Inhibits Invasion and Exhibits Potential in Human Breast Cancer Therapy. Sci. Rep. 3, 3098. doi: $10.1038 /$ srep03098

Liu, Z., Cai, C., Du, J., Liu, B., Cui, L., Fan, X., et al. (2020). TCMIO: A Comprehensive Database of Traditional Chinese Medicine on ImmunoOncology. Front. Pharmacol. 11, 439. doi:10.3389/fphar.2020.00439

Loi, S., Dushyanthen, S., Beavis, P. A., Salgado, R., Denkert, C., Savas, P., et al. (2019). RAS/MAPK Activation Is Associated with Reduced Tumor-Infiltrating Lymphocytes in Triple-Negative Breast Cancer: Therapeutic Cooperation between MEK and PD-1/pd-L1 Immune Checkpoint Inhibitors. Clin. Cancer Res. 25 (4), 1437. doi:10.1158/1078-0432.CCR-15-1125

Ma, Y., and Wink, M. (2008). Lobeline, a Piperidine Alkaloid from Lobelia Can Reverse P-Gp Dependent Multidrug Resistance in Tumor Cells. Phytomedicine 15 (9), 754-758. doi:10.1016/j.phymed.2007.11.028

Maleki, S. J., Crespo, J. F., and Cabanillas, B. (2019). Anti-inflammatory Effects of Flavonoids. Food Chem. 299, 125124. doi:10.1016/j.foodchem

Mittendorf, E. A., Philips, A. V., Meric-Bernstam, F., Qiao, N., Wu, Y., Harrington, S., et al. (2014). PD-L1 Expression in Triple-Negative Breast Cancer. Cancer Immunol. Res. 2 (4), 361-370. doi:10.1158/2326-6066.CIR-13-0127

Mu, Y., Zhou, C. H., Chen, S. F., Ding, J., Zhang, Y. X., Yang, Y. P., et al. (2016). Effectiveness and Safety of Chemotherapy Combined with Cytokine-Induced Killer Cell/dendritic Cell-Cytokine-Induced Killer Cell Therapy for Treatment of Gastric Cancer in China: A Systematic Review and Meta-Analysis. Cytotherapy 18 (9), 1162-1177. doi:10.1016/j.jcyt.2016.05.015

Oh, J., Yoon, H. J., Jang, J. H., Kim, D. H., and Surh, Y. J. (2019). The Standardized Korean Red Ginseng Extract and its Ingredient Ginsenoside Rg3 Inhibit Manifestation of Breast Cancer Stem Cell-like Properties through Modulation of Self-Renewal Signaling. J. Ginseng Res. 43 (3), 421-430. doi:10.1016/j.jgr.2018.05.004

Pan, X., Zhao, B., Song, Z., Han, S., and Wang, M. (2016). Estrogen Receptor-A36 Is Involved in Epigallocatechin-3-Gallate Induced Growth Inhibition of ERNegative Breast Cancer Stem/progenitor Cells. J. Pharmacol. Sci. 130 (2), 85-93. doi:10.1016/j.jphs.2015.12.003

Pan, Y., Zheng, Q., Ni, W., Wei, Z., Yu, S., Jia, Q., et al. (2019). Breaking Glucose Transporter 1/Pyruvate Kinase M2 Glycolytic Loop Is Required for Cantharidin Inhibition of Metastasis in Highly Metastatic Breast Cancer. Front. Pharmacol. 10, 590. doi:10.3389/fphar.2019.00590

Pantelidou, C., Sonzogni, O., De Oliveria Taveira, M., Mehta, A. K., Kothari, A., Wang, D., et al. (2019). PARP Inhibitor Efficacy Depends on CD8+ T-Cell Recruitment via Intratumoral STING Pathway Activation in BRCA-Deficient Models of Triple-Negative Breast Cancer. Cancer Discov. 9 (6), 722-737. doi:10.1158/2159-8290

Pareja, F., and Reis-Filho, J. S. (2018). Triple-negative Breast Cancers - a Panoply of Cancer Types. Nat. Rev. Clin. Oncol. 15 (6), 347-348. doi:10.1038/s41571-018$0001-7$
Park, E. J., Min, H. Y., Chung, H. J., Hong, J. Y., Kang, Y. J., Hung, T. M., et al. (2009). Down-regulation of C-Src/EGFR-Mediated Signaling Activation Is Involved in the Honokiol-Induced Cell Cycle Arrest and Apoptosis in MDA-MB-231 Human Breast Cancer Cells. Cancer Lett. 277 (2), 133-140. doi:10.1016/j.canlet.2008.11.029

Pettitt, S. J., Frankum, J. R., Punta, M., Lise, S., Alexander, J., Chen, Y., et al. (2020). Clinical BRCA1/2 Reversion Analysis Identifies Hotspot Mutations and Predicted Neoantigens Associated with Therapy Resistance. Cancer Discov. 142 (6), 2699-2703. doi:10.1021/jacs.9b10510

Ramamoorthy, P., Dandawate, P., Jensen, R. A., and Anant, S. (2021). Celastrol and Triptolide Suppress Stemness in Triple Negative Breast Cancer: Notch as a Therapeutic Target for Stem Cells. Biomedicines 9 (5), 482. doi:10.3390/ biomedicines 9050482

Ren, G., Shi, Z., Teng, C., and Yao, Y. (2018). Antiproliferative Activity of Combined Biochanin A and Ginsenoside Rh2 on MDA-MB-231 and MCF-7 Human Breast Cancer Cells. Molecules 23 (11), 2908. doi:10.3390/ molecules 23112908

Romero, D. (2019). Benefit in Patients with PD-L1-Positive TNBC. Nat. Rev. Clin. Oncol. 16 (1), 6. doi:10.1038/s41571-018-0127-7

Song, L., Liu, D., Zhao, Y., He, J., Kang, H., Dai, Z., et al. (2018). Sinomenine Reduces Growth and Metastasis of Breast Cancer Cells and Improves the Survival of Tumor-Bearing Mice through Suppressing the SHh Pathway. Biomed. Pharmacother. 98, 687-693. doi:10.1016/j.biopha.2017.12.065

Takei, M., Tachikawa, E., Hasegawa, H., and Lee, J. J. (2004). Dendritic Cells Maturation Promoted by M1 and M4, End Products of Steroidal Ginseng Saponins Metabolized in Digestive Tracts, Drive a Potent Th1 Polarization. Biochem. Pharmacol. 68 (3), 441-452. doi:10.1016/j.bcp.2004.04.015

Tan, H., Zhang, G., Yang, X., Jing, T., Shen, D., and Wang, X. (2020). Peimine Inhibits the Growth and Motility of Prostate Cancer Cells and Induces Apoptosis by Disruption of Intracellular Calcium Homeostasis through Ca2+/CaMKII/JNK Pathway. J. Cel Biochem 121 (1), 81-92. doi:10.1002/ jcb. 28870

Tegowski, M., and Baldwin, A. (2018). Noncanonical NF-Kb in Cancer. Biomedicines 6 (2), 66. doi:10.3390/biomedicines6020066

Tsai, C. H., Yang, C. W., Wang, J. Y., Tsai, Y. F., Tseng, L. M., King, K. L., et al. (2013). Timosaponin AIII Suppresses Hepatocyte Growth Factor-Induced Invasive Activity through Sustained ERK Activation in Breast Cancer MDAMB-231 Cells. Evid. Based Complement. Alternat Med. 2013, 421051. doi:10.1155/2013/421051

Ullmannova, V., and Popescu, N. C. (2007). Inhibition of Cell Proliferation, Induction of Apoptosis, Reactivation of DLC1, and Modulation of Other Gene Expression by Dietary Flavone in Breast Cancer Cell Lines. Cancer Detect. Prev. 31 (2), 110-118. doi:10.1016/j.cdp.2007.02.005

Wang, J., Yang, X., Han, H., Wang, L., Bao, W., Wang, S., et al. (2018). Inhibition of Growth and Metastasis of Triple-Negative Breast Cancer Targeted by Traditional Chinese Medicine Tubeimu in Orthotopic Mice Models. Chin. J. Cancer Res. 30 (1), 112-121. doi:10.21147/j.issn.1000-9604.2018.01.12

Wang, P., Song, D., Wan, D., Li, L., Mei, W., Li, X., et al. (2020). Ginsenoside Panaxatriol Reverses TNBC Paclitaxel Resistance by Inhibiting the IRAK1/NFKb and ERK Pathways. PeerJ 8, e9281. doi:10.7717/peerj.9281

Wang, P., Yang, Q., Du, X., Chen, Y., and Zhang, T. (2019). Targeted Regulation of Rell2 by microRNA-18a Is Implicated in the Anti-metastatic Effect of Polyphyllin VI in Breast Cancer Cells. Eur. J. Pharmacol. 851, 161-173. doi:10.1016/j.ejphar.2019.02.041

Wang, Y., Sui, Y., and Tao, Y. (2019). Gambogic Acid Increases the Sensitivity to Paclitaxel in Drug-Resistant Triple-Negative Breast Cancer via the SHH Signaling Pathway. Mol. Med. Rep. 20 (5), 4515-4522. doi:10.3892/ mmr.2019.10697

Wang, Y., Zhang, Q., Chen, Y., Liang, C. L., Liu, H., Qiu, F., et al. (2020). Antitumor Effects of Immunity-Enhancing Traditional Chinese Medicine. Biomed. Pharmacother. 121, 109570. doi:10.1016/j.biopha.2019.109570

Wild, C. A., Bergmann, C., Fritz, G., Schuler, P., Hoffmann, T. K., Lotfi, R., et al. (2012). HMGB1 Conveys Immunosuppressive Characteristics on Regulatory and Conventional T Cells. Int. Immunol. 24 (8), 485-494. doi:10.1093/intimm/ dxs051

Xu, H., Hu, M., Liu, M., An, S., Guan, K., Wang, M., et al. (2020). Nano-puerarin Regulates Tumor Microenvironment and Facilitates Chemo- and 
Immunotherapy in Murine Triple Negative Breast Cancer Model. Biomaterials 235, 119769. doi:10.1016/j.biomaterials.2020.119769

Yao, M., Fan, X., Yuan, B., Takagi, N., Liu, S., Han, X., et al. (2019). Berberine Inhibits NLRP3 Inflammasome Pathway in Human Triple-Negative Breast Cancer MDA-MB-231 Cell. BMC Complement. Altern. Med. 19 (1), 216. doi:10.1186/s12906-019-2615-4

Yi, X., Lou, L., Wang, J., Xiong, J., and Zhou, S. (2021). Honokiol Antagonizes Doxorubicin Resistance in Human Breast Cancer via miR-188-5p/FBXW7/ c-Myc Pathway. Cancer Chemother. Pharmacol. 87 (5), 647-656. doi:10.1007/ s00280-021-04238-w

Yoon, Y. D., Han, S. B., Kang, J. S., Lee, C. W., Park, S. K., Lee, H. S., et al. (2003). Toll-like Receptor 4-dependent Activation of Macrophages by Polysaccharide Isolated from the Radix of Platycodon Grandiflorum. Int. Immunopharmacol 3 (13-14), 1873-1882. doi:10.1016/j.intimp.2003.09.005

Yu, K. D., Ye, F. G., He, M., Fan, L., Ma, D., Mo, M., et al. (2020). Effect of Adjuvant Paclitaxel and Carboplatin on Survival in Women with Triple-Negative Breast Cancer: A Phase 3 Randomized Clinical Trial. JAMA Oncol. 6 (9), 1390-1396. doi:10.1001/jamaoncol.2020.2965

Yu, X., Lao, Y., Teng, X. L., Li, S., Zhou, Y., Wang, F., et al. (2018). SENP3 Maintains the Stability and Function of Regulatory T Cells via BACH2 deSUMOylation. Nat. Commun. 89 (1), 3157. doi:10.1038/s41467-018-05676-6

Yuan, Z., Jiang, H., Zhu, X., Liu, X., and Li, J. (2017). Ginsenoside Rg3 Promotes Cytotoxicity of Paclitaxel through Inhibiting NF-Kb Signaling and Regulating Bax/Bcl-2 Expression on Triple-Negative Breast Cancer. Biomed. Pharmacother. 89, 227-232. doi:10.1016/j.biopha.2017.02.038

Yumimoto, K., Akiyoshi, S., Ueo, H., Sagara, Y., Onoyama, I., Ueo, H., et al. (2015). F-box Protein FBXW7 Inhibits Cancer Metastasis in a Non-cell-autonomous Manner. J. Clin. Invest. 125 (2), 621-635. doi:10.1172/JCI78782

Zhang, M., Qu, J., Gao, Z., Qi, Q., Yin, H., Zhu, L., et al. (2021). Timosaponin AIII Induces G2/M Arrest and Apoptosis in Breast Cancer by Activating the ATM/ Chk2 and P38 MAPK Signaling Pathways. Front. Pharmacol. 11, 601468. doi:10.3389/fphar.2020.601468

Zhang, Y., Lou, Y., Wang, J., Yu, C., and Shen, W. (2021). Induced Expression of PD-1, a Novel Member of the Immunoglobulin Gene Superfamily, upon Programmed Cell Death. Front. Immunol. 11, 609705. doi:10.3389/ fimmu.2020.609705

Zhang, Y., Zhang, T. J., Li, X. Y., Liang, J. W., Tu, S., Xu, H. L., et al. (2021). 2-((1Phenyl-1H-1,2,3-triazol-4-yl) Methyl)-2-Azabicyclo [3.2.1] Octan-3-One Derivatives: Simplification and Modification of Aconitine Scaffold for the Discovery of Novel Anticancer Agents. Eur. J. Med. Chem. 210, 112988. doi:10.1016/j.ejmech.2020.112988
Zhang, Y., Zou, B., Tan, Y., Su, J., Wang, Y., Xu, J., et al. (2019). Sinomenine Inhibits Osteolysis in Breast Cancer by Reducing IL-8/CXCR1 and C-Fos/ NFATc1 Signaling. Pharmacol. Res. 142, 140-150. doi:10.1016/ j.phrs.2019.02.015

Zhang, Z., Sun, C., Zhang, L., Chi, X., Ji, J., Gao, X., et al. (2019). Triptolide Interferes with XRCC1/PARP1-Mediated DNA Repair and Confers Sensitization of Triple-Negative Breast Cancer Cells to Cisplatin. Biomed. Pharmacother. 109, 1541-1546. doi:10.1016/j.biopha.2018.11.008

Zhao, L., and Zhang, C. (2020). Berberine Inhibits MDA-MB-231 Cells by Attenuating Their Inflammatory Responses. Biomed. Res. Int. 2020, 3617514. doi:10.1155/2020/3617514

Zhao, Y., Jing, Z., Lv, J., Zhang, Z., Lin, J., Cao, X., et al. (2017). Berberine Activates Caspase-9/cytochrome C-Mediated Apoptosis to Suppress Triple-Negative Breast Cancer Cells In Vitro and In Vivo. Biomed. Pharmacother. 95, 18-24. doi:10.1016/j.biopha.2017.08.045

Zhou, J., Kryczek, I., Li, S., Li, X., Aguilar, A., Wei, S., et al. (2021). The Ubiquitin Ligase MDM2 Sustains STAT5 Stability to Control T CellMediated Antitumor Immunity. Nat. Immunol. 22 (4), 460-470. doi:10.1038/s41590-021-00888-3

Zhu, X., Wang, K., and Chen, Y. (2020). Ophiopogonin D Suppresses TGF-B1Mediated Metastatic Behavior of MDA-MB-231 Breast Carcinoma Cells via Regulating ITGB1/FAK/Src/AKT/ß-catenin/MMP-9 Signaling axis. Toxicol. Vitro 69, 104973. doi:10.1016/j.tiv.2020.104973

Conflict of Interest: The authors declare that the research was conducted in the absence of any commercial or financial relationships that could be construed as a potential conflict of interest.

Publisher's Note: All claims expressed in this article are solely those of the authors and do not necessarily represent those of their affiliated organizations, or those of the publisher, the editors and the reviewers. Any product that may be evaluated in this article, or claim that may be made by its manufacturer, is not guaranteed or endorsed by the publisher.

Copyright $\odot 2021$ Zhao, Liu, Li, Chen, Qi and Zhang. This is an open-access article distributed under the terms of the Creative Commons Attribution License (CC BY). The use, distribution or reproduction in other forums is permitted, provided the original author(s) and the copyright owner(s) are credited and that the original publication in this journal is cited, in accordance with accepted academic practice. No use, distribution or reproduction is permitted which does not comply with these terms. 